\title{
Palpitation and virtual-assisted lung mapping: not mutually exclusive but complementary to facilitate sublobar lung resection
}

\author{
Masahiro Yanagiya, Masaaki Sato \\ Department of Thoracic Surgery, The University of Tokyo Graduate School of Medicine, Tokyo, Japan \\ Correspondence to: Masaaki Sato. Department of Thoracic Surgery, The University of Tokyo Graduate School of Medicine, Tokyo, Japan. \\ Email: SATOM-SUR@h.u-tokyo.ac.jp. \\ Response to: Goto T. Virtual-assisted lung mapping: is it actually better than finger palpation? J Thorac Dis 2021;13:414-6.
}

Submitted Mar 25, 2021. Accepted for publication Apr 14, 2021.

doi: $10.21037 /$ jtd-21-522

View this article at: http://dx.doi.org/10.21037/jtd-21-522

We thank Goto T. for the valuable comments on the limitations and problems of virtual-assisted lung mapping (VAL-MAP) and the claim that finger palpation is superior to this technique in response to our recent paper about VAL-MAP $(1,2)$. We wish to make four points to support our contention that VAL-MAP is necessary.

First, we did not intend to discount the value of conventional palpation in association with the use of VALMAP. Although we did not clearly state this in our original paper, we often use palpation in combination with VALMAP. In our opinion, Goto's statement that "(in the use of VAL-MAP,) the operators cannot directly determine the tumor location by touch" (1) revealed a misunderstanding of aspects of the practical use of VAL-MAP. To the best of our knowledge, most surgeons using VAL-MAP also confirm the location of a tumor, especially when that tumor is palpable (e.g., a solid nodule), by palpation using either a finger or metal suction probe, even when VALMAP markings have been perfectly placed. Additionally, if a tumor is easily palpable, we generally do not bother to perform VAL-MAP.

Second, palpation cannot precisely locate some tumors. As many Japanese experts have reported, some pulmonary tumors are impalpable $(3,4)$. One of these authors $(\mathrm{MY})$ reported an impalpable tumor that finally required lobectomy rather than wedge resection and turned out to be benign (5). Indeed, the statement "In our experience, most tumors are palpable, even in case of pure ground-glass neoplasms (1)," suggests that Goto has encountered impalpable tumors. The most important question that thoracic surgeons then face is how to deal with an impalpable tumor. Furthermore, it is not always possible to accurately predict the intraoperative palpability of a pulmonary nodule. For example, even though a tumor appears likely to be palpable on CT images, palpation may be hindered by a neighboring scar or fibrosis. Another group recently reported a case in which VALMAP greatly facilitated accurate resection of pulmonary metastases in a patient who had previously undergone open thoracotomy (6). During surgery, extensive tight adhesions were encountered. After dissecting these adhesions, the metastatic tumors were indistinguishable from thick fibrotic pleura by finger palpation, whereas VAL-MAP markings enabled localization of the tumors (6). As shown in multiple observational studies and case series, palpation is not always reliable (3-5). At minimum, palpation depends largely on the surgeons' skills and experience, limiting its accuracy when performing pulmonary resections. We consider that VALMAP minimizes such limitations, making sublobar lung resection more reliable and reproducible. We have sometimes regretted not having performed VAL-MAP after finding it difficult to palpate a tumor during surgery, whereas we have never regretted having performed VAL-MAP.

Third, the invasiveness and complications of VALMAP need to be addressed carefully; in Goto's letter "invasiveness" was not clearly defined (1). It is true that bronchoscopic procedures, including VAL-MAP, involve some invasiveness and can cause complications. However, no procedure is better than VAL-MAP in this respect. As we have discussed above, technical assistance is sometimes needed to localize a pulmonary nodule. CT-guided placement of a hookwire is a conventional means of localization; however, it has the potentially 
Table 1 Inclusion criteria for virtual-assisted lung mapping

Patients with a suspected or diagnosed pulmonary malignant tumour for which thoracoscopic sub-lobar lung resection (wedge resection or segmentectomy ${ }^{\mathrm{a}}$ ) is indicated

and

- The tumour is expected to be hardly identifiable during surgery, including but not limited to

- A pure ground glass nodule

- A nodule $<5 \mathrm{~mm}$ in diameter

- A nodule whose diameter is less than the distance to the closest pleural surface and/or

- Resection lines that need especially accurate demarcation for visualization during surgery, including but not limited to

- A nodule with a ground glass component, the extension of which is expected to be hardly identifiable during surgery

- A nodule for which extended or complex segmentectomy is necessary

${ }^{\mathrm{a}}$ The surgical procedure was selected by the surgeon(s), taking multiple factors into consideration including, but not limited to: suspected diagnosis (primary or metastatic), estimated degree of malignancy (e.g., \% of ground glass components in CT scan), the location of the tumour (close to the pleural surface or not) and patient's comorbidities.

fatal major limitation of risking air embolism, which was one of the motivations for developing VAL-MAP (7). We have published a systematic review of bronchoscopic marking techniques, including VAL-MAP, in which we demonstrated that bronchoscopic marking procedures have never resulted in serious complications; however, there may have been some publication bias (8). Additionally, although it has been claimed that one advantage of the palpation method is a shorter surgical time (1), a previous study has reported that VAL-MAP shortens surgical time (9). Indeed, as many thoracic surgeons have experienced, localization by palpation is usually quick and easy; however, when it is not, the procedure can become extremely time consuming and even nightmarish.

Fourth, in our studies we rigorously defined successful resections as complete resection of target tumors with resection margins larger than or equal to the lesion diameter, or $\geq 2 \mathrm{~cm}$ if the tumor was larger than $2 \mathrm{~cm}$ $(2,7)$. Although unsuccessful resection rates were as high as $8.2 \%$, the study was retrospective and normally inadequate resection margins were not regarded as clinically unacceptable in some cases (e.g., a 15-mm diameter pure ground glass nodule with a $12-\mathrm{mm}$ resection margin).

One of the challenges in previous studies using VALMAP has been setting an appropriate control; this has resulted in the issue of effect size, as pointed out by Goto (1). It is easy to propose conducting a randomized controlled trial, but not so easy to achieve. We believe that it would be unrealistic and even unethical to perform a randomized controlled trial to compare VAL-MAP with the palpation method for the following reasons. First, it would not be a simple comparison between VAL-MAP and palpation, but rather a comparison of palpation with or without VAL-MAP, as was mentioned above. Second, as discussed above, we believe that palpation alone is not always reliable and that VALMAP should be used if the targeted nodule meets the criteria for performing VAL-MAP listed in Table 1 of one of our studies (10) and reproduced here. These criteria have been devised for lesions that cannot reliably be palpated. Third, once VAL-MAP is conducted routinely, it would not be realistic to operate without it, particularly when a targeted nodule meets the indications for VAL-MAP. Indeed, our group discussed planning such a study; however, most surgeons disagreed with the idea, stating that it would not be ethical to plan surgery accompanied by palpation alone, given that VAL-MAP is readily available and an established technique with minimal risks.

\section{Acknowledgments}

We thank Dr. Trish Reynolds, MBBS, FRACP, from Edanz Group (https://en-author-services.edanz.com/ac) for editing a draft of this manuscript.

Funding: This work was funded by the Japan Agency for Medical Research and Development. 


\section{Footnote}

Provenance and Peer Review: This article was a standard submission to the journal. The article did not undergo external peer review.

Conflicts of Interest: Both authors have completed the ICMJE uniform disclosure form (available at http://dx.doi. org/10.21037/jtd-21-522). Both authors have no conflicts of interest to declare.

Ethical Statement: The authors are accountable for all aspects of the work in ensuring that questions related to the accuracy or integrity of any part of the work are appropriately investigated and resolved.

Open Access Statement: This is an Open Access article distributed in accordance with the Creative Commons Attribution-NonCommercial-NoDerivs 4.0 International License (CC BY-NC-ND 4.0), which permits the noncommercial replication and distribution of the article with the strict proviso that no changes or edits are made and the original work is properly cited (including links to both the formal publication through the relevant DOI and the license). See: https://creativecommons.org/licenses/by-nc-nd/4.0/.

\section{References}

1. Goto T. Virtual-assisted lung mapping: is it actually better than finger palpation? J Thorac Dis 2021;13:414-6.

2. Yanagiya $M$, Sato $M$, Ueda K, et al. Preoperative lung surface localization for pulmonary wedge resection: a

Cite this article as: Yanagiya $M$, Sato M. Palpitation and virtual-assisted lung mapping: not mutually exclusive but complementary to facilitate sublobar lung resection. J Thorac Dis 2021;13(6):3927-3929. doi: 10.21037/jtd-21-522 single-center experience. J Thorac Dis 2020;12:2129-36.

3. Suzuki K, Nagai K, Yoshida J, et al. Video-assisted thoracoscopic surgery for small indeterminate pulmonary nodules: indications for preoperative marking. Chest 1999;115:563-8.

4. Tamura $M$, Oda $M$, Fujimori $H$, et al. New indication for preoperative marking of small peripheral pulmonary nodules in thoracoscopic surgery. Interact Cardiovasc Thorac Surg 2010;11:590-3.

5. Hashimoto H, Yanagiya M, Suzuki Y, et al. A case of solitary pulmonary capillary hemangioma indicating true gross appearance. Pathol Int 2017;67:322-3.

6. Yanagiya $M$, Amano $Y$, Hiyama $N$, et al. Initial experience of virtual-assisted lung mapping utilizing both indocyanine green and indigo carmine. Gen Thorac Cardiovasc Surg 2021;69:1035-9.

7. Sato M, Kobayashi M, Kojima F, et al. Effect of virtualassisted lung mapping in acquisition of surgical margins in sublobar lung resection. J Thorac Cardiovasc Surg 2018;156:1691-701.

8. Yanagiya $M$, Kawahara T, Ueda K, et al. A meta-analysis of preoperative bronchoscopic marking for pulmonary nodules. Eur J Cardiothorac Surg 2020;58:40-50.

9. Kuwata T, Shinohara S, Matsumiya H, et al. Virtualassisted lung mapping (VAL-MAP) shortened surgical time of wedge resection. J Thorac Dis 2018;10:1842-9.

10. Sato M, Kuwata T, Yamanashi K, et al. Safety and reproducibility of virtual-assisted lung mapping: a multicentre study in Japan. Eur J Cardiothorac Surg 2017;51:861-8. 